\title{
VIVIR EL "AQUÍ Y AHORA”, PASA POR TRANSFORMARTE
}

Teresa Carbonell Yonfá ${ }^{1}$

Estudiante de Maestría en Poder y Desarrollo,

mención en Movimientos Sociales

Universidad Politécnica Salesiana

Ver la ciencia con la óptica del artista, y el arte, con la de la vida.

F. Nietzsche

Intentar una reflexión sobre el arte desde una concepción que trasciende su función puramente estética, es un camino recorrido a lo largo de la historia y cuyo horizonte ha sido advertido desde varias visiones.

Desde los clásicos (con Platón y Aristóteles a la cabeza), siguiendo con los modernos (Cassirer, Schiller), los contemporáneos (Gadamer, Jung), y los posmodernos (Read, Lowenfeld), entre otros, se han realizado aportes a la función y esencia del arte para la humanidad.

El presente trabajo parte de refrescar las miradas $y$, en su recorrido, delinear reflexiones sobre la importan-

1 La autora es Comunicadora Social para el Desarrollo (UPS). Diplomada en Participación Política, Gestión y Desarrollo en el ámbito local (Universidad de Valencia, España, en coordinación con la UPS). 
cia de su presencia en el sistema formal de aprendizaje vinculante como método formativo. Método que consolide una filosofía en la enseñanza, que trastoque las mecanicidades memorísticas, rígidas, insertas en el sistema formal cognitivo. Una nueva filosofía que fortalezca los saberes del sentir, y permita al sujeto acceder a aprendizajes liberadores.

\section{El segundo capturado de varias horas de refle- xiones filosóficas}

Toda cultura que olvida sus mitos, pierde su potencial hacedor.

Nietzsche

El arte a diferencia de la ciencia no puede reducirse a un conocimiento claro y distinto de su objeto. Es por ello que cuando el artista experimenta cierta sensación de fracaso ante su obra, no es tanto por la incompetencia, sino por la desmesurada ambición por catalogarla como obra de precisión, mas esta no es su función; por el contrario, se acerca a la reflexión, la meditación, a través de la motivación y el encantamiento que emana de su centro interior.

Desde el siglo pasado, la posición del artista en la sociedad es incómoda (sobre todo si no acepta convertirse en un productor de mercancías) y su hostilidad al sistema social es manifiesta. En la actualidad, es evidente que el arte se encuentra en inferioridad de condiciones para competir con la ideología dominante. Vivimos una época en la que proliferan microchips producto de una civilización tecnocrática que rechaza los valores éticos y estéticos, deforma el intelecto, desintegra las formas artísticas y las oferta como mercancías fetiches de estatus.

No es menos cierto que cuando nos situamos frente a una obra de arte difícilmente conseguimos dejar 
de lado conceptos que han tomado forma a lo largo de los siglos - aunque sería inadecuado someter los testimonios materiales del pasado a los criterios que empleamos en el presente-, obviamente porque no podemos olvidar que cada época asignó al arte un papel distinto y muy diferente al que hoy le atribuimos.

Lo que el árbol tiene de frondoso, se lo debe a lo que lleva sepultado. Así el arte de hoy vive del arte del ayer, de sus técnicas, de su evolución en la inexorable historia. El símbolo artístico significa un estado del mundo; puede invitar a sobrepasarlo o a volver a una etapa anterior quizás un poco más o un poco menos estetizada.

Cuando hablamos de la estética nos referimos al arte en sus múltiples categorías, en las que coexisten lo bello, lo sublime, lo cómico, lo trágico con cada una de sus manifestaciones que varían según la mirada interna de cada espectador.

Platón, en su claro dualismo ontológico: el mundo sensible y el mundo inteligible o mundo de las ideas, concibe a la mímesis como parte de este último; es decir, no como la representación de cosas materiales sino como la de encarnar formas perceptibles de estas ideas (léanse "unidades extramentales") independientes del hombre; "las ideas son causas de las cosas" (Diccionario Filosófico, 1871: 2) que se ven opacadas por un mundo corrupto, voluptuoso, que no ejercita el espíritu ni el cuerpo y por ello son "débiles e incapaces", más no por ello son débiles e incapaces de resistir el placer y dolor (Roucek, 1870: 33).

Este filósofo ya anotaba también en su obra $\mathrm{La}$ República que el arte deber ser la base de la educación. A través del mito de la caverna hace la metáfora de nuestra naturaleza e ilustra y cuestiona el conocimiento; al igual que los prisioneros de la caverna que sólo ven las sombras 
de los objetos, nosotros vivimos en la ignorancia cuando nuestras preocupaciones se refieren al mundo que se ofrece a los sentidos.

Aristóteles, por su parte, atribuía al hombre la necesidad innata de imitar ya no las ideas sino la realidad, así como las acciones y pasiones humanas. En esta perspectiva, los griegos demostraron que el arte podría servir de verdadero lugar estratégico para reflejar la vida y desde este ejercicio aprehenderla mejor. "La finalidad del arte es dar cuerpo a la esencia secreta de las cosas, no de copiar su apariencia" (Aristóteles).

Marcuse decía que el mundo puede ser entendido desde dos dimensiones: desde el logos que encierra todo lo racional y somete a la naturaleza a un proceso lógico y sofisticado; y el epos que comprende lo emotivo, la fantasía, lo natural, todo lo que fluye. Si bajo esta perspectiva damos una mirada al sistema educativo imperante en nuestras sociedades, pregunto: ¿Cuál fue el motivo para que la tendencia mayoritaria en el mundo, al momento de formar a sus ciudadanos, haya privilegiado el logos al epos e instalado la solemnidad casi temeraria en las aulas? Una reflexión que amerita destapar los preceptos del oscurantismo y toda la estructura montada para defender dogmas y el ejercicio del poder presente en todas las etapas de la humanidad.

Read piensa que "la inteligencia libre de cualquier tipo de prejuicio intelectual resulta capaz de asimilarla en su completa totalidad" (Read, 1973: 262), y la forma sostenida con que el hombre puede liberarse de la opresión del $\log o s$ es a través del arte, porque es el único que alberga en su esencia valores auténticos, naturales, que poseen la fuerza necesaria para otorgarle el verdadero sentido a su razón de ser: su existencia. Desde la mirada por Read, la dimensión activa, revolucionaria del arte es la 
condición necesaria de su presencia en el mundo, dado que todo lo que permanece estancado está condenado a la destrucción.

Según la estética lúdica de Schiller, el arte y la vivencia estética son presentados como un reto a la racionalidad científica y técnica, a las que atribuye un carácter represivo (Schiller, 1772: 157). De esta manera, el arte y la estética se vinculan al principio del placer que rige en nuestra psiquis desde sus orígenes y están en oposición al principio de la realidad que nos impone el mundo exterior y su sistema. Por ello es que se puede evidenciar el enfrentamiento evidente en nuestros días del arte con la realidad cotidiana. También establece que lo artístico y lo estético se identifican con el impulso del juego, y logran una síntesis de los impulsos sensoriales y racionales con los de la razón y viceversa (Schilller, 1772: 110-121). La reflexión inmediata a la que me lleva este aporte de Schiller es que si el arte es capaz de integrar internamente al individuo, también puede ser capaz de unir a la humanidad entera, pues el hombre es una partícula del todo.

Bajo la visión freudiana se puede develar la relación que tiene el hombre con la cultura burguesa, que lejos de ser la sabia de la cual el sujeto se nutre y es parte constitutiva, ella representa el cántaro alucinógeno que lo obliga a beber, y en esta condición lo objetiviza para lograr su permanencia en ella y accionar sobre él. Así, la relación individuo-sociedad se manifiesta hostil. La sociedad está inmersa en un caos al que arrastra al hombre. El proceso de su adaptación es complejo y enfermizo dado que debe someter su personalidad a las reglas sociales y rígidas que guardan una linealidad que penaliza lo diferente frente a lo establecido (Freud, 1930: 75).

De esta forma se va generando una nueva cultura que radicaliza la ambición de poseer, acumular y con- 
sumir, exaltando el individualismo y la competencia. El ser se objetiva a sí mismo a medida que se ve como un elemento más dentro de un gran mercado y actúa movido por las dinámicas que en él se producen.

El conjunto de frustraciones que experimenta el individuo, los sufrimientos espirituales y trastornos psíquicos que desequilibran su personalidad, se derivan de esta agresión constante de la que es víctima y parte a la vez. Empero, dicha hostilidad es el impulso más efectivo para protestar, para cuestionar, se convierte en el ADN que corre por las venas de todo artista; a la postre, con su hostigante asecho, la sociedad burguesa terminará formando un ejército de cinceles, plumas, pinceles, cuerdas... locas y locos que se tomarán el mundo de la fantasía, la armonía y la disonancia, encontrando un lugar para simplemente ser.

El psicoanálisis freudiano devela desde sus interpretaciones del sueño que este es la realización de un deseo que contiene invariablemente un mensaje oculto relacionado con la sexualidad de quien sueña; ahora bien, para entender el significado de lo oculto y la distorsión es preciso entender el papel de la represión que se relaciona con la propia formación del sujeto, en el lenguaje, en lo simbólico. Dicho esto, me atrevo a pensar que el hombre al despertar de su profundo sueño continúe soñando en los brazos del arte, ensueño de lo eterno, de la libertad, de la propia vida en sentido infinito que crea y recrea, que juega con las formas humanas y captura sus instintos profundos, sin identidad ni juicio.

Atribuir al artista el papel del nuevo filósofo, como lo hizo Heidegger es un acierto: el poder de expresión del arte es infinito, multifacético. La genialidad capturada en inagotables formas, activan en cualquier neurona, hormona o sentido, sensaciones con diversos destinos. Únicamente el arte resulta capaz de interrumpir el irre- 
versible proceso de destrucción, es la fuerza que lucha de manera permanente con la situación existencial (Heidegger, 1996: 67-75). Situar al arte como una necesidad vital puede ser el distintivo de la supremacía de la raza humana.

La estética burguesa trató el arte y la realidad como dos categorías aisladas; es decir, niega que el arte es reflejo de un devenir del hombre y su momento histórico (Ovsiannikov, 1978: 11). Esta concepción es la que ha primado y, se puede decir, ha quitado al arte la posibilidad de estar presente de forma significativa en el proceso formativo del ser; apenas se le otorgó la categoría de un «plus». En principio, no olvidemos que el arte nace y permanece mucho tiempo elitizado. Hoy el arte ha permeado más en la clase media, pero como mecanismo de sobrevivencia, adaptado al mercado; es decir, vinculado más al trabajo que a la magia o al mito.

Bergson toma el arte como intuición; opina que este posee una fuerza misteriosa, llamada intuición, que trasciende el campo emocional que nace en el instinto de su creador y se revela por el instinto de su espectador (Bergson, 1907: 89). "No hay ninguna separación de principio entre la propia afirmación de la obra de arte y el que la experimenta" (Gadamer, 1995).

Para Jung, el artista no busca el símbolo para designar aquello que resulta claro, lo crea para desentrañar lo no evidente, lo subconsciente. Lo simbólico; no intenta remitirnos a un fin con un significado predeterminado.

El artista no es una persona que busca sus propios fines, sino que es un instrumento para que el arte realice sus propios fines. Como ser humano tiene caprichos, excentricidades y visiones personales, pero como artista es un hombre en el sentido más elevado, un hombre colectivo, aquel que lleva y moldea la vida psíquica 
inconsciente del género humano. «La obra de arte, como el sueño y el mito, es la desembocadura de varios ríos que confluyen, es la finalidad manifiesta de las potencialidades creadoras del Inconsciente» (Jung, 1981: notas).

Desde la visión psicológica, el arte se manifiesta profundamente, pues los símbolos, las imágenes juegan de manera directa en la psiquis. Ellos recrean situaciones que los individuos no se atreven a decir, pensar o denunciar; y al verlos representados en la obra, se sienten escuchados, aliviados de saber que sus deseos no son de otro planeta, que existen miles de almas atormentadas, sedientas de amor; espíritus que sufren ante la impotencia y otros más libres que se revelan y se muestran irreverentes ante la crueldad del mundo, la injusticia, la impunidad; seres que reclaman un lugar digno en esta tierra, un espacio azul o quizás rojo, un espacio, en fin, donde puedan soñar despiertos y en libertad.

El origen del arte para Levis-Strauss se encuentra en la combinación del mito primitivo con la habilidad técnica. La función mágica del arte ha llegado hasta nuestros días, y para que el objeto artístico pudiera ser considerado como un fin en sí mismo ha sido necesario desprenderlo de su sentido mágico originario. Su reconocimiento social e institucional se ha dado en la medida en que se ha reconocido el carácter diferenciado del arte. Hoy sentimos la necesidad de integrar al arte toda su dimensión mítica porque el mito se resiste a la historia: es eterno, se resiste a lo estático: se renueva con cada generación humana.

Si bien el lenguaje y el arte son productos de la imitación (mímesis), el primero de sonidos y el otro de cosas exteriores, los mitos representan las creencias que elucubra la mente que pueden o no estar contenidos en la realidad externa. Los mitos pueden ser expresados en palabras o símbolos, son la expresión del mundo interno. 
Uno de los campos donde el arte incide de manera significativa es en la cultura. Siendo la cultura el todo (las costumbres, el conocimiento, la formación, religión, la tecnología y sus usos, la evolución del ser humano en cada uno de los espacios de la tierra y el producto de lo que se atreve a soñar y a representar), el arte asume un papel determinante por el poder que detenta en la representación y la creación permanente desde lo natural, que difiere en forma de la visión instrumental de la tecnología. El arte transforma todo ser de la naturaleza en un ser de la cultura (Lévi-Strauss, 1974: 212).

La tecnología devasta la cultura, rompiendo la producción manual y sus usos, que debilita el poder de accionar de manera directa entre el ser y la naturaleza. No así el arte que hace posible mirar más allá de lo establecido y mantiene viva la esencia cambiante de la cultura.

Breacht, dada su vinculación con lo teorizado al interior del marxismo, hace la clásica vinculación de la mímesis con el conocimiento: la teoría del reflejo de Lenin. La representación de los personajes y caracteres típicos del realismo social, los hechos esenciales de la historia de la sociedad en un momento y lugar concretos, viendo en ellos la mejor forma de develar las fuerzas que impulsan a esta. Es decir, que el arte desde su función representativa, como parte del ritual, entra orgánicamente en la realidad social. En sintonía con esta dimensión, Cassirer afirmaba que el arte no es una mera reproducción de una realidad acabada (imitación), sino descubrimiento de la realidad. Así, el arte nos revela características de la cotidianidad que no nos fijamos en el ir y venir; es decir, «miramos a diario el mundo que nos rodea sin verlo» (Cassirer, 1967: 131).

Entonces, el arte llena este vacío cuando el espectador-oyente se sumerge en ese pedazo de arte y se detiene a meditar sobre los contenidos, los detalles, los 
sentidos que contiene esa obra, ese trozo o renglón, y lo conecta con el aún más desconocido mundo de los sentidos internos.

Una obra que es catarsis del creador origina cadena de catarsis en el espectador; lo interesante radica en lograr que la catarsis trascienda a la acción creativa y movilice otras pistas por donde hacer camino hacia la conciencia que busca trascender.

Gadamer sostenía que las fragmentos de realidad que el arte extrae, no son receptados por un espectador pasivo, sino que el arte demanda una labor de construcción interna. El símbolo puede tener sus orígenes en el mundo conocido y sugerir algo aún desconocido, o simplemente del mundo desconocido para sugerir algo conocido o inimaginable (Gadamer, 1991: 84-100). Aquí radica la fenomenología del arte desde donde sobrepasar los cánones de la ética, de la moral, que permita al ser humano salir de la falsedad de la reproducción y las buenas costumbres hacia la dimensión utópica-soñada, posible o no posible.

Ya lo mencionó Kant, que no importa que el objeto que provoca la experiencia estética exista realmente o no, sino que la motive. Finalmente son los sentidos que captan y el cerebro que elabora el sentido de las percepciones de acuerdo al proceso de vida y experimentación con el medio. Esto ya es otro filtro creado por una experiencia real o no real, pero procesado en el mundo de las abstracciones que, además se traducen, buena parte, en mecanicidades que son las que hay que observar para avanzar.

Cuando hablamos de la posibilidad de la transformación de la humanidad, hablamos de elevar el nivel de conciencia humana. Esta posibilidad obedece a todo un proceso que despoje al individuo de sus propias meca- 
nicidades a través del conocimiento de sí mismo que lo lleve a sentir de manera personal e intentar una observación permanente y reflexiva de los actos cotidianos libres de prejuicios y presiones sociales.

$\mathrm{El}$ individuo ha venido perdiendo su capacidad de expresión y, por ende, sus estructuras en colectivo. El aislamiento al que cotidianamente se enfrenta desde la tecnología y el ritmo de la rutina no le permiten repasar ni revaluar sus capacidades, que se pierden en la extensión del relativismo parco.

Urgen formas cotidianas que entrañen componentes nuevos, vivos, que logren remover el aletargamiento y la desesperanza que habita entre esas esquinas retorcidas, abandonadas a la propia suerte de sus solitarios transeúntes. El arte en su diversidad es capaz de motivar este tipo de cambios porque trastoca el centro del individuo y es más fuerte aún cuando activa el corazón del colectivo.

Actuar en colectivo implica la asimilación de las necesidades sociales, práctica que compromete pero a la vez libera. Esta libertad la encontramos en la medida que podemos expresar nuestras aspiraciones; el arte lo perifonea con la creatividad y permite que se exprese desde el vértice del sentir el producto de lo que somos o representamos y lo que queremos ser, sentir-hacer. Nos permite liberar lo que estaba cautivo y reprimido, lo agencia a mover, a renovar.

Bajo este ejercicio de libertad compartida es posible llegar a construir nuevas identidades sin apellidos, sin fronteras; identidades universales permeadas por el buen trato al otro y, por ende, a nosotros mismos.

Sólo en la medida en que nos reconocemos, podemos conocer y respetar el espíritu humano y podemos provocar la interacción, la asociación con la realidad 
circundante. Realizar esta conectividad requiere del uso de los sentidos, y es el arte el que afina, despierta y los mantiene vivos.

Actuar desde la libertad del ser puro implica también otorgar un sentido al bienestar colectivo: el todo influye a la parte y viceversa, de manera dialéctica. La pregunta que surge es: ¿por qué si de manera teórica y reflexiva se ha llegado a precisar esta verdad, no ha existido en la historia forma de conducirlo hacia una realización planetaria?

En la antigua Grecia, la Filosofía fue el todo universal, y, más adelante, en la Edad Media, la religión fue tomada como la única capaz de proporcionar la idea general y teórica de la existencia del mundo, así como la ciencia y la técnica en la Edad Moderna son las que dominan aún esa totalidad; ¿será que esta modernidad tardía (Habermas, 1988: 6) sea la que permita al arte constituirse en el ente aglutinador, consensuador y unificador de lo existente?

\section{Educarte para transformarte}

Luego de este breve recorrido extractivo de los sentires de varios pensadores, vemos razones válidas para hacer del arte el motor interno que movilice la transformación humana. Nos queda mirar la forma de implementarlo y de hacer posible que permee desde los microespacios de convivencia su magia y el juego que es parte de él también.

La educación, entendida sobre todo en su dimensión formativa, es la llamada a adoptar el arte como eje transversal, como método, como punto de inflexión que filtre todo contenido y toda reflexión.

La importancia de vincular al arte en la educación es para disponer de un modo natural de integración, 
para amalgamar de manera cabal la percepción y el sentimiento de todos, por despertar los sentidos y la sensibilidad que produce esa unidad de conciencia.

El arte produce felicidad personal y armonía social, condiciones básicas para el aprendizaje, que genere principalmente sabiduría no tanto conocimiento. La lógica necesita complementarse con la imaginación. La creatividad abre todo una autopista con decenas de carriles para continuar el viaje hacia el descubrimiento de la vida que mejor nos venga, que nos dé un sentido real y nos lleve a la transformación ontológica permanente.

La necesidad de expandir las estrategias motivadoras en las mentes de maestras y maestros se hace urgente; la voluntad política es importante para las transformaciones que vendrán en el mediano y largo plazo; se necesita la voluntad del maestro para que cambié él y la realidad en el aula. Deben primar los acuerdos que en ella se logran con la participación directa de maestros/as y alumnos/as, pues es en cada realidad local donde se producen los grandes cambios que se ven en la historia.

Hasta nuestros días, el arte no ha logrado representar la subjetividad colectiva, pero porque no lo hemos permitido. Es momento de empezar en las aulas preservando las facultades mentales, despertando esos sentidos, invirtiendo en la liberación del niño, adolescente y jovensujeto desde sus propias capacidades artísticas.

Ojalá las paredes escolares, colegiales y universitarias, hoy llenas de afiches, escudos y normas a observar, sean cambiadas por grafitis, por garabatos, por espacios donde solo el crayón sin juicio sea capaz de habitar y ese ejercicio permanente logre su expresión, porque cada frase escrita públicamente comunica y da apertura a otras construcciones sociales.

Sería interesante que las clases de Filosofía incorporen más sociodramas y representaciones teatrales 
de los filósofos clásicos y modernos, para conocer su pensamiento $y$, a la vez, piramidar nuevas filosofías desde nuestras realidades y necesidades.

... las clases de la inexorable Historia hablen 20 minutos de lo pasado y los 25 restantes de la historia presentiva; donde los alumnos opinen sin temor al disparate sobre nuevas fórmulas de hacer un mejor presente; y mañana ya no hablar de la inexorable Historia sino de la historia que fue posible y que quisimos que sea. Recrearla a través de pintura, el teatro, títeres, etcétera, y poner imágenes a través de los sentidos.

... y las clases de Matemáticas sumen más iniciativas de cálculos aplicados a la vida real con situaciones prácticas con materiales construidos entre todos en espacios lúdicos y, por otro lado, se dejen de ver los ejercicios en la burbuja perfecta de un sólo resultado. Que tengan la posibilidad de saber que el producto final puede ser diferente para cada uno si nos atrevemos a imaginar — solos o en colectivo-, y que lo importante está en el proceso y no tanto en el resultado.

Ojalá las "reinas de belleza" trasciendan la concepción de la estética simple y se coronen en otras categorías más alcanzables para todos, como el humor, la imaginación, la tolerancia, donde medie el sentido de participación y no el de la competencia.

Permitámonos reavivar el espíritu del arte que habita en nosotros y aprendamos a sentir y celebrar más los pequeños logros del día a día. A festejar el instante que pasa y nos permite re-pensar y re-significar. Catarsear solos o en colectivo cuando en el camino logramos identificar el porqué hacemos algo de determinada manera y qué nos moviliza, y finalmente pintar, modelar o acompasar los detalles de las nuevas pistas incorporadas. 


\section{Algunas conclusiones}

El arte es para transformarse a sí mismo, para la transformación social.

El arte es esencialmente humano: el no lugar para sentir.

Carbonell

- Siendo la educación el proceso mediante el cual los seres humanos se forman de manera general, es vital perfilar un programa de educación mediante el arte, porque a través de él será posible la revolución moral, la libertad de acción y, sobre todo, la libertad de emoción.

- El arte debe ser hoy un lugar real lejos de vitrinas, de museos, de expediciones y galerías, debe cambiar la vida de otros «artistas y no artistas», debe cambiar estructuras, paradigmas, sistemas enteros. Debe ser un lugar para ser y sentir, más que existir y razonar.

- Transgredir el arte es transformar, sobrepasar lo pasado, sobrevenir lo inmensurable, abrir ventanas parabólicas, paracúbicas, para el campo, para uno, para tres, para que entre el rayo de otras claridades y pillarnos otras formas de alumbrar.

- El arte es el escenario donde se crea la magia con arena de las ruinas egipcias y la varita de crayón del primer grado, donde tanto artista como espectador controle la obra al punto de desmontarla.

- El arte hoy debe tomar el riesgo como bastidor y la imaginación como pincel para desdibujar lo estatuido, lo predecible y delinear mil pasos cebras invertidos que te crucen, de vez en cuando, hacia lados opuestos. 
- El arte debe componer el solfeo que descompase al reloj del tiempo y pare en la hora de cualquier día, para cuando el niño quiera grafitear la estética académica que más le combine al color que imagina.

- El arte debe servir para liberarnos de todo lo prohibido y con nuestras mentes romper los límites y volar sobre ellos.

Alcanzar sociedades más justas pasa por cambios estructurales donde la formación del ser en su esencia es la base. El arte posibilita esta nueva construcción, por su capacidad holística que lo contiene y genera, por su poder creativo en crecimiento y permanente transformación.

\section{Bibliografía}

BERGSON, Henry

1907 La Evolución creativa.

CASIRIER, Ernst

1967 Antropología filosófica. Introducción a una filosofía de la cultura. México: ed. Fondo de cultura económica.

DICCIONARIO FILOSÓFICO

1871 Resumen del pensamiento de los filósofos y escuelas filosóficas más importantes. Torre de Babel Ediciones.

GADAMER, Hans Georg

1991 La actualidad de lo bello. España: ed. Paidós.

HABERMAS, Jürgen

1988 Teoría de la acción comunicativa, I y II. ed. Taurus. Madrid. España.

HIDEGGER, Martín

1996 El Origen de la Obra de Arte. Trad. Helena Cortez. Caminos de Bosque. Alianza.

JUNG, Carl

1981 Collected Works, Vol VIII, New York: Princeton University Press. 
OVSIANNIKOV, Mike

1970 La teoría del reflejo y la estética.

READ, Herbert

1973 Educación por el arte. ed. España. Paidós.

SCHILLER, Friedrich

1772 Sobre la educación estética del hombre. Berlín.

FREUD, Sigmund

1930 El malestar de la cultura, copyright: http//www.librodot. com 